\title{
Systematic Identification, Implementation, and Evaluation of High-Leverage Practices in Teacher Preparation
}

\section{Andrew Markelz, Benjamin Riden, and Lawrence Maheady}

\begin{abstract}
An emphasis on practice-based teacher education has led the Council for Exceptional Children (CEC) to develop 22 high-leverage practices (HLPs). Each HLP is research-based, used frequently in classrooms, and applicable across age, grade, and content area. In this article, we discuss the importance of a systematic process for teacher preparation programs to consider when identifying, implementing, and evaluating HLPs. The extent and quality that HLPs are integrated within preparation programs will affect graduating teachers' professional readiness and their ability to immediately affect student outcomes. It is our intent that this article supports teacher educators and scholars to continue the conversation around HLPs in teacher preparation. In addition, we encourage preparation programs to consider data-based decision making when identifying, implementing, and evaluating HLPs within program curricula.
\end{abstract}

\section{Keywords}

high-leverage practices, special education, teacher preparation

An era of practice-based teacher education (PBTE) is upon us (Leko et al., 2015; McDonald et al., 2013). The PBTE movement emerged initially from the National Council for Accreditation in Teacher Education (NCATE) blue ribbon panel's recommendation to turn teacher education "upside down" by embedding preparation in clinical practice (NCATE, 2010). It was fueled by internal and external criticism of teacher education's limited impact on teacher practice and student learning (Farkas \& Duffett, 2010; Lignugaris/Kraft et al., 2014); a proliferation of alternative paths to certification and licensure (Sindelar et al., 2014); and rapid changes in accountability and accreditation policies and standards (CAEP, 2017). The movement was also stimulated by better evidence to support teachers' positive effects on student learning. States and colleagues (2012) noted that more credible support can be found in research using (a) effect sizes (Forness, 2001; Dunst et al., 2020; Hattie, 2009), (b) value-added modeling (Rowan, 2004), and (c) randomized controlled trials (Nye et al., 2004). Other potential contributors to PBTE included (a) state and national policies linking teacher evaluation to student learning gains (Maheady et al., 2013), (b) positive effects of coaching and performance feedback on instructional practice (Kretlow \& Bartholomew, 2010), and (c) the emergence of a "practice-based evidence" approach to applied research (Barkham \& Margison, 2007; Cook \& Cook, 2016).

Practice-based teacher education refers to an approach to preparation that makes teaching practicewhat teachers $d o$ instructionally-the central element of the curriculum (Zeichner, 2012). PBTE programs are characterized by clinically rich field experiences and strong school-university partnerships (Hauser \& Kavanaugh, 2019) and their implementation is changing the nature, structure, and function of teacher preparation. PBTE has prompted substantive curricular and pedagogical changes (Pugach et al., 2014); spurred on the creation and/or expansion of P-12 school-university partnerships (CAEP, 2017); and increased calls for more rigorous, classroom-based research addressing problems of "practice" (Belfiore \& Lee, 2016). One interesting area of change has been the development of high leverage practices (HLPs).

Windschitl and colleagues (2012) defined HLPs as, "a set of practices that are fundamental to support student learning, and that can be taught, learned, and implemented by those entering the profession" (p.880). These practices focus directly on instruction or behavior, are research-based, used frequently in classrooms, and applicable across content areas, age- and grade-levels. HLPs can also serve as a core curriculum for teach- 
er preparation and graduation requirements for beginning teachers (Ball \& Forzani, 2009; Grossman et al., 2009; Windschitl et al., 2012).

While PBTE and HLPs are laudable developments, the devil remains in the details about how teacher educators should proceed. For example, which HLPs and how many should be adopted? On what basis should they be selected? How can they be aligned with existing accreditation standards and program requirements? How should HLPs be taught, and can they be used for initial preparation and/or professional development (Bryk, 2009; McLeskey \& Billingsley, 2008)? Can HLPs be implemented with integrity, examined with rigor, and sustained over time? If so, how? These are just a few questions confronting teacher educators.

This article addresses some of these concerns using three broad questions: (a) How can teacher preparation programs systematically identify which HLPs to teach? (b) How can preparation programs teach and implement them well? and (c) How can preparation programs evaluate the identification and implementation of HLPs? We used CEC's (2017) HLPs as a focus of discussion and describe events surrounding their development. We offer potential selection options and a decision-making matrix to facilitate discussion. How to systematically identify HLPs is discussed in terms of (a) identifying important and common sub-components and subskills, and (b) describing a decision-making matrix to assist in implementation. Finally, we discuss a method of progress monitoring that allows for nuanced analysis of HLP implementation and provides useful data for preparation programs and researchers.

\section{Identifying High Leverage Practices to Teach}

The CEC (2017) published a set of 22 HLPs that "represent the essence of effective practice in special education" (p. 11). Each HLP is described as applicable and important to the everyday work of special education teachers (SETs) and they are organized around four domains: (a) collaboration, (b) assessment, (c) social/ emotional/behavioral, and (d) instruction (CEC, 2017; See Figure 1). The implication for teacher educators is that beginning SETs should acquire these practices with some degree of proficiency prior to exiting preparation programs.
Figure 1. List of HLPS by Domain

\section{High Leverage Practices by Domain}

\section{Collaboration}

HLP1 - Collaborate with professionals to increase student success.

HLP2 - Organize and facilitate effective meetings with professionals and families.

HLP3 - Collaborate with families to support student learning and secure needed services.

\section{Assessment}

HLP4 - Use multiple sources of information to develop a comprehensive understanding of a student's strengths and needs.

HLP5 - Interpret and communicate assessment information with stakeholders to collaboratively design and implement educational programs.

HLP6 - Use student assessment data, analyze instructional practices, and make necessary adjustments that improve student outcomes.

\section{Social / Emotional / Behavioral}

HLP7 - Establish a consistent, organized, and respectful learning environment.

HLP8 - Provide positive and constructive feedback to guide students' learning and behavior. HLP9 - Teach social behaviors.

HLP10 - Conduct functional behavioral assessments to develop individual student behavior support plans

\section{Instruction}

HLP11 - Identify and prioritize long- and short-term learning goals.

HLP12 - Systematically design instruction toward a specific learning goal.

HLP13 - Adapt curriculum tasks and materials for specific learning goals.

HLP14 - Teach cognitive and metacognitive strategies to support learning and independence.

HLP15 - Provide scaffolded support.

HLP16 - Use explicit instruction.

HLP17 - Use flexible grouping.

HLP18 - Use strategies to promote active student engagement.

HLP19 - Use assistive and instructional technologies.

HLP20 - Provide intensive instruction.

HLP21 - Teach students to maintain and generalize new learning across time and settings.

HLP22 - Provide positive and constructive feedback to guide students' learning and behavior.

\section{Which HLPs to Embed in Curriculum?}

There are many ways to proceed in selecting and embedding HLPs in preparation programs. Options can range from making systemic programmatic changes by embedding all 22 HLPs across coursework and clinical experiences, to identifying a "core" set of HLPs to infuse in some courses (e.g., methods \& student teaching), to infusing one or a few HLPs into individual courses taught by interested and motivated faculty. Ultimately, decisions about how to proceed will be made based on local, contextual factors (e.g., faculty skill sets, availability, and interest/institutional support on campus and in P-12 schools). The intent here is to explore possible consequences associated with different options.

It is likely - but not yet documented - that various HLPs are already being taught and practiced to some degree in existing preparation programs and/or courses; a predictable consequence of PBTE and the broad dissemination of HLPs products and resources (e.g., CEC, 
2017). Initially, preparation programs should conduct baseline assessments to determine the extent to which HLPs are being taught and/or developed in existing coursework and clinical experiences. The Collaboration for Effective Educator Development, Accountability, and Reform (CEEDAR) Center has developed important tools and resources (i.e., practice guides and clinical planning templates) to assist teacher educators in pedagogical redesign around the use of HLPs (Benedict, Foley et al., 2016; Benedict, Holdheide, 2016). Information derived from baseline assessments can inform decision-making regarding HLP use.

\section{Holistic Approach}

A holistic approach to program redesign promotes the adoption and embedding of all 22 HLPs throughout the curriculum and clinical experiences. This approach is comprehensive in that it targets important skill sets across all practice domains (collaboration, assessment, instruction, and social/emotional/behavior development), infuses HLPs throughout the curriculum and clinical experiences, and engages most, if not all, faculty in the delivery and evaluation of HLPs. Building preparation around all 22 HLPs should increase program coherence and better align the program with certification/licensure and accreditation standards (i.e., discussed later). A holistic approach may prove challenging to implement, however, given competing curricular demands, limited time frames, and conflicting faculty views on PBTE and HLPs. It may also be overwhelming for faculty to teach and preservice SETs to learn all 22 HLPs while meeting other certification and/ or accreditation requirements.

\section{Signature Set of Practices}

A second option to consider in program redesign is to adopt and embed a smaller number of core or signature practices (e.g., 5 to 10) and maximize SET opportunities to use them throughout the curriculum. A set of high priority HLPs can be identified based on importance and relevance within the local context and targeted with more intense implementation (Maheady \& Patti, 2020). During clinical experiences, for example, preservice SETs can learn to work collaboratively to plan and deliver high quality lessons (HLPs 10 \& 11), use strategies that actively engage students (HLP 17), provide positive and corrective feedback (HLP 21), and use student assessment data to monitor student progress (HLP 5). These skill sets can be practiced and/or expanded in subsequent clinical experiences throughout the program.

The core approach highlights the importance of a signature set of skills and allocates additional time for their development and refinement. Programmatic decisions must be made regarding which HLPs to prioritize, where they will be embedded in the program, and how they will be taught and evaluated. Teaching SETs to use fewer HLPs at greater depth may be a more pragmatic and feasible approach, but care must be taken to ensure exposure to other important but nonprioritized HLPs.

\section{Individualized Approach}

Some teacher educators may find themselves in programs where they have limited influence over the curriculum and/or few colleagues interested in using HLPs in programs and/or courses. In these instances, they can experiment by using one or more (i.e., signature) HLPs in their own courses. Individual efforts to move HLPs from theory into practice-if done and documented with rigor-may provide useful implementation models and fill an empirical void in teacher preparation literature (see for example, Patti et al., 2021).

\section{Role of Professional Teaching Standards}

Many special education programs look to CEC's initial preparation standards to ensure accreditation requirements are being met. CEC's Performance-Based Initial Preparation Standards define what a candidate must know and be able to do to begin teaching (CEC, 2015). More recently, CEC released the 2020 Initial Practice-Based Professional Preparation Standards for Special Educators (CEC, 2020a). With updated standards and component statements, the 2020 revisions include a narrowed focus on preparing educators who will be working with students in kindergarten through 12th grade. Acknowledging that SET preparation programs use CEC standards for accreditation, and the increasing emphasis of HLPs, CEC created a "cross-walk" between CEC standards and HLPs (CEC, 2020b). This cross-walk is another tool that preparation programs can use to identify where CEC standards and HLPs are already addressed and/or are missing. The cross-walk tool can be found here https://highleveragepractices. org/standards/cross-walks.

\section{When and Where to Embed HLPs in Programs}

While HLPs are being identified, questions regarding when and where they are taught can be addressed. Should all HLPs be at least introduced in one or more semesters and covered minimally? Can specific HLPs 
(e.g., signature practices) be interwoven into relevant courses and clinical experiences? How can core HLPs be embedded repeatedly throughout coursework and clinical experiences? Should some HLPs be infused in campus-based instruction and others during clinical experiences? Given time constraints in most preparation programs these questions and others must be addressed based on local contextual factors (e.g., faculty interests and skill sets). Generally, HLPs should be introduced as early as possible in the preparation program, interwoven through coursework and clinical experiences, include multiple opportunities to practice, and receive performance-based feedback as often as possible (Maheady et al., 2019).

Figure 2. Decision-Making Model on When and Where to Implement HLPS

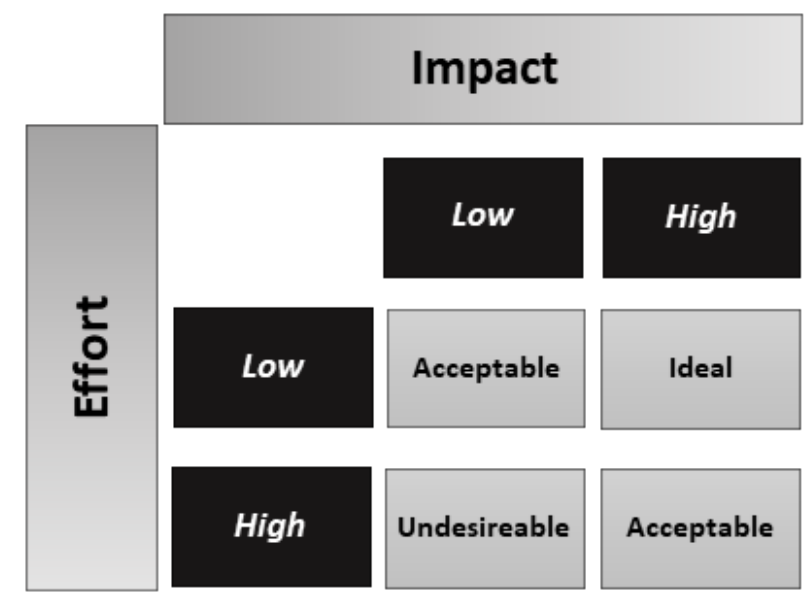

Figure 2 offers a decision-making matrix that teacher educators might use when considering when and where to introduce and/or teach selected HLPs. The two main components-effort and impact-represent variables that practitioner can weigh in the decision-making process. Effort refers to the amount of resources (e.g., time, money, and skills) needed to implement specific HLPs. For example, a preparation program that already has a course on assistive technology and partners with local schools that serve students with assistive technology needs would probably require less effort to implement HLP 19-use assistive and instructional technologies - than a program that has neither in place. Similarly, it may take less effort to teach SETs to lead effective meetings (HLP 2) than to prepare them to create consistent, organized, and respectful learning environments (HLP 7).
Impact refers to the potential effects that HLPs have directly on preservice SETs practice and indirectly on the academic and/or behavioral performance of students with disabilities. Impact will vary as a function of important HLP (a) features (e.g., complexity, extent of empirical support, and importance and relevance to local context), (b) skill sets and beliefs of those who teach and use them, and (c) how well they are taught. Some HLPs, for example, may be easier to teach and learn because they are less procedurally complex (e.g., HLP 11 -identify and prioritize long and short-term objectives - versus HLP 20-provide intensive instruction); some may have bigger impact because they have more empirical support (e.g., HLP 18-use strategies that promote active student engagement - versus HLP 5interpreting and communicating assessment information with stakeholders); and some HLPs may produce greater change in SET practice and student learning because they are more important and relevant to local needs. The goal is to select the most impactful HLPs and teach them in the most effective ways.

Effort and impact exist on a continuum between low and high which creates four domains for programmatic decision-making around HLPs selection. These domains can assist programs in making decisions about when and where to embed HLPs throughout a program. An extensive discussion of the nature and functions of effort and impact and possible outcomes associated with their interactions is beyond the scope of this paper. However, we offer some general guidelines and examples.

In theory, "low effort" HLPs require less time, money, and support (i.e., professional development) and fewer curricular and pedagogical changes to implement, than "high effort" HLPs which necessitate additional time, money, training, and/or programmatic changes. Some HLPs may also require less effort to implement because they - or their primary componentsalready exist in curriculum; are consistent with faculty and program goals and vision; and/or are delivered collaboratively with school-university partners (Maheady et al., 2019). High impact HLPs would produce noticeable changes in SET practice and/or student learning, while those with low impact would show little or no change(s) in teaching practice and/or student learning.

Ideally, teacher educators would select and use low effort/high impact HLPs as much as possible and avoid practices that require high effort yet yield little impact. High impact/high effort HLPs would also be preferable 
over those practices requiring high effort but producing little impact. We assume that effort and impact will vary considerably depending on local context, however, offer a few examples for illustrative purposes.

Consider HLP 18-use strategies to promote active student engagement-SETs can learn about various strategies in university settings (e.g., choral responding, peer assisted tutoring, and response cards) and role-play scenarios with their peers. This may be seen as high effort (using valuable instructional time) but low impact if preservice teachers "practice" without authentic experiences. Implementing these strategies in front of K-12 students during field experiences, however, may have greater impact on SET's practice and improve "real" students' learning. In addition, research suggests that providing SETs with positive and constructive feedback during authentic practice experiences facilitates skill acquisition and progress through subsequent learning phases (Cornelius \& Nagro, 2014).

In contrast, HLP 5-interpret and communicate assessment information with stakeholders to collaboratively design and implement educational programsmay be more appropriately implemented (i.e., low effort and high impact) in a structured university course with prescribed case studies. The acquisition and fluency of this HLP may benefit from scaffolded instruction where instructors pause assignments and reflect on teachable moments (high impact), as opposed to real-time, authentic, meetings with stakeholders (high effort).

\section{How to Implement High Leverage Practice}

To become skilled users of HLPs, preservice SETs will require structured and repeated opportunities to apply their knowledge in authentic settings while receiving performance feedback (Leko et al., 2015). Although many preparation programs have developed clinical experiences over the years, too often teacher educators had limited influence over the (a) quality of those placements and/or (b) types of skills preservice SETs learned in them (McDonald et al., 2013; McLeskey \& Brownell, 2015). As such, Ericsson (2014) argued for more deliberate practice; that is, carefully designed practice opportunities that increase in complexity and decrease in level of candidate support. Although the exact number and nature of these experiences has not been well-articulated, Ericsson suggested that teaching opportunities should be (a) sequenced developmentally to allow candidates to assume greater instructional responsibilities as they proceed through the program; (b) linked to P-12 student needs whenever possible; and (c) monitored regularly for fidelity of implementation and impact on student learning.

How can teacher educators target critical components of HLPs to foster proficient use by preservice SETs? Here, we suggest that HLPs contain evidence-based kernels to varying degrees and that they should be the focus of instruction. A better understanding of behavioral kernels is fundamental to effective HLP use and effectiveness and the identification of preparation practices that facilitate their acquisition and application.

\section{Evidence-Based Kernels}

Evidence-based kernels are any indivisible procedures shown through experimental evaluation to produce reliable effects on behavior (Embry, 2004). The term derived from a series of meetings where several prevention scientists and policy leaders sought to denominate the 'active ingredients' fundamental to an intervention's effectiveness (Embry \& Biglan, 2008). The unit of a kernel, according to Embry and Biglan, is indivisible, and if any of its components are eliminated, the practice would prove ineffective. Examples of evidence-based kernels identified through research included self-monitoring (Agran et al., 2005; Hughes et al., 2002), timeout (Fabiano et al., 2004; Kazdin, 1980), overcorrection (Maag et al., 1986), and peer tutoring (Maheady et al., 1988).

We suggest that evidence-based kernels exist within each HLP and that they should be the focus of teaching. For example, HLP 21-teach students to maintain and generalize new learning across time and settings-describes multiple strategies to achieve these outcomes (e.g., program common stimuli and train sufficient exemplars), yet no one strategy will work all the time with every student. We propose that systematic programming for generalization is a behavioral kernel within the HLP and teaching SETs to actively program for generalization will increase the probability that student skills will generalize. Instructionally, teacher educators would emphasize systematic planning for generalization as the kernel and the use of one or more specific generalization strategies as exemplars. It is true that knowing each generalization strategy is important and likely the first step in teaching HLP 21. The evidence-based kernel of HLP 21, however, is the intentional planning skills required to implement any generalization strategy.

Consider HLP 17-use flexible grouping-as an- 
other example. The authors write, "Teachers assign students to homogenous and heterogeneous groups based on explicit learning goals, monitor peer interactions, and provide positive and corrective feedback to support productive learning" (CEC, 2017, p. 82). While SETs learn to implement homogeneous (i.e., same ability) and heterogeneous (i.e., mixed ability) groups, it is critical that they understand when and where to use each grouping strategy. Homogeneous grouping, for example, appears to be more effective for high performing and/or gifted learners (Vogl \& Preckel, 2014), while heterogeneous groups are more beneficial for low and average performers (Hattie, 2009). An evidence-based kernel for effective flexible grouping, therefore, is the intentionality of achieving specified learning objectives. One way to teach this HLP would be to practice creating and implementing flexible grouping objectives.

\section{Evaluating the Success of Identifying and Implementing HLPS}

The decision-making matrix (Figure 2) may also assist in identifying effective and efficient ways to prepare SETs to implement HLPs. While evidence-based kernels can guide the content of HLP instruction (i.e., what is taught), ongoing evaluation and analysis are required to determine the efficacy of preparation practices. There are at least two benefits to evaluating (i.e., progress monitoring) HLP implementation. First, teacher educators can make more informed decisions as to whether identification and implementation are progressing as effectively as possible, and second, educational researchers can document preparation practices that facilitate HLP implementation. Luckily, teacher educators do not have to begin from scratch.

Dunst and colleagues (2020) recently completed extensive meta-analyses that examined the impact of 14 different types of preparation practices (e.g., methods of course delivery, teaching method of instruction, and clinical experiences) on two different measures of teacher quality (i.e., teacher behavior and performance appraisals). They reported that findings were consistent with practice-based approaches to teacher education that emphasized active and extended preservice teacher learning opportunities, faculty and supervisor coaching with performance feedback, and repeated opportunities to refine core teaching practices (e.g., use of HLPs). To provide a more fine-grained analysis, we propose a systematic method to document intervention effectiveness and isolate independent variables for functional analyses.

\section{Component Analysis vs. Treatment Packages}

Researchers face a paradox when conducting intervention science (Riden et al., 2020). On one hand, they want to enact change for the betterment of participants. Whether an intervention is introduced to promote social skills of students with autism or HLPs are taught to increase SETs instructional readiness, interventions are designed to affect positive change. Interventions are built upon evidence-based practices or kernels (sometimes in combination) to produce the greatest amount of change. Conducting a 60-min professional development session to prepare SETs to use effective classroom management strategies, for example, may result in positive change. However, combining that training with daily self-monitoring procedures and positive/ constructive feedback (i.e., multi-component intervention package) may strengthen intervention effects. The downside is that these intervention packages are often more difficult to implement, reduce implementation fidelity, and are less likely to be adopted and used by practitioners (Riley-Tillman \& Chafouleas, 2003). Additionally, multi-component packages muddle researchers' abilities to isolate active ingredients and document which independent variables contributed to overall effect (Riden et al., 2020).

A component analysis is a systematic evaluation of two or more independent variables that encompass a treatment package (Cooper et al., 2020). The benefit of a component analysis for HLP implementation is that researchers can systematically identify the active ingredients contributing to successful implementation. Unnecessary components can then be eliminated as treatment packages are streamlined which, in turn, may make them more easily adopted and implemented. One drawback to component analyses is that they can be quite time consuming. Individual HLP components must be isolated and evaluated within an appropriate methodological design. To do so, reversal phases are needed to document behavior changes when intervention components are added or removed.

Cooper et al (2020) noted there were two methods of conducting component analyses; drop-out and addin. A drop-out analysis presents an intervention package as a whole then removes each component systematically. Any changes in behavior following a removal indicate the effects of that component in relation to the 
entire package (i.e., student performance is the same, better, or worse). An advantage to drop-out analyses is that treatment effects are often immediate and subsequent removals can identify those parts that are essential to treatment effectiveness (Riden et al., 2020).

One major disadvantage to drop out analyses is that they are not appropriate for nonreversible behaviors; that is, learned behaviors that are likely to continue after instruction is stopped (Ledford et al. 2019). For example, once preservice SETs learned the definition and benefits of behavior-specific praise, they cannot unlearn that knowledge. Once a treatment package is implemented, learned behaviors would not likely reduce even if an essential component was withdrawn. Therefore, add-in component analyses might be a more appropriate alternative.

Add-in component analyses assess individual components before presenting the whole intervention package (Cooper et al., 2020). By presenting components alone and then in combination, researchers can identify which components are contributing to overall intervention effects. The main disadvantage of add-in component analyses is that floor or ceiling effects may make it difficult to assess individual component efficacy towards the end of the analyses (Riden et al., 2020). Ward-Horner and Sturmey (2010) concluded that addin reversal or alternating treatments designs provide the most comprehensive analyses of treatment packages because they reduce potential confounding from component combinations. However, multiple baseline designs may be more useful when targeting behaviors that are not reversible.

Add-in component analyses may allow preparation programs to identify HLP parts that are necessary for effective implementation. For example, consider HLP 9- conduct functional behavioral assessments to develop individual student behavior support plans - and our proposed decision-making model. Teacher educators may initially implement this HLP by lecturing on functional behavior assessments (component 1), practicing through case studies (component 2), and then conducting real-life functional behavior assessments during student teaching (component 3). One can also envision possible sub-components (e.g., length and content of lecture and the type and quality of feedback during case study practice/student teaching experiences). Although increasing effort (i.e., time and resources) at each component will likely increase impact (i.e., preservice teacher learning), add-in analyses may help to identify whether all three components are necessary and/or what resource efforts are necessary for preservice candidates to achieve HLP proficiency.

\section{Moving Forward}

As universities make programmatic decisions around identification, implementation, and evaluation of HLPs, we suggest the following initial steps.

\section{Programmatic Steps}

Most special education departments have curriculum (i.e., or ad hoc) committees charged with certification/licensure responsibilities. We recommend SET preparation programs use CEC's crosswalk (CEC, 2020b) and CEEDAR developed tools (Benedict, Foley et al., 2016; Benedict, Holdheide, 2016) to (a) conduct baseline program assessments to identify implemented, partially implemented, and non-implemented HLPs and (b) guide programmatic redesign to infuse HLPs into the curriculum and clinical experiences.

Following initial HLP review, curriculum committees should prioritize HLP integration. The individual nature of university programs and personnel, and other important contextual variables, should guide decision-making. Some important questions to address are (a) Should all HLPs be introduced early in the program, then practiced more thoroughly within certain courses? (b) Should HLPs only be introduced within a course where extensive practice can take place? and (c) Are there certain HLPs (i.e., signature) that preservice teachers should have repetitive practice throughout multiple courses? Hopefully, the decision-making matrix can assist in the decision-making process.

\section{Individual Instructor Steps}

Once HLPs are in place, individual instructors are tasked with the actual teaching and implementation of HLPs. We recommend that instructors use an evidence-based kernel mindset. That is, they should identify and teach critical HLP component(s). Critical HLP components require preservice SETs to master HLPs and components that are most likely to affect the greatest change. For example, HLP 19 states that effective teachers use assistive and instructional technologies. While knowledge of available assistive and instructional technologies is an important aspect of HLP 19, it is not an evidence-based kernel. Rather the critical component of effectively implementing HLP 9 is the ability to "evaluate new technology options given student needs; make informed instructional decisions grounded 
in evidence, professional wisdom, and students' IEP goals. .." (CEC, 2017). The decision-making process of identifying appropriate assistive and instructional technologies based on individual student needs is the behavioral kernel that preservice teachers must master. Instructors, therefore, should dedicate sufficient instruction, practice, and evaluation to the development of instructional decision-making skills concerning assistive and instructional technology.

Ongoing progress monitoring of preservice SETs use of selected HLPs is also necessary for "informed" programmatic and instructor decision making. We described component analyses (add in and drop out) as one systematic way to evaluate HLP implementation. While it is unrealistic to expect instructors to design well-controlled research studies to evaluate HLP use, they might approach implementation with a progress monitoring mindset and require preservice SETs to collect formative data on the impact of their HLPs on important student outcomes. These data, in turn, might be used to facilitate instructional decision-making (Maheady et al., 2007).

\section{Research Field Steps}

Although course instructors are less likely to conduct formal evaluations of HLP implementation, teacher education researchers should employ rigorous HLP research. The systematic study of HLP implementation and evaluation is sorely needed and can move the field towards more effective and efficient HLP integration. Granular examinations of individual HLPs and evidence-based kernels can provide teacher educators and researchers with valuable information to address some of the questions raised earlier. Component analyses of HLPs should also assist researchers and practitioners in increasing implementation impact while minimizing effort.

Research derived from HLP implementation should be shared by those responsible for SET preparation. Intervention successes and failures can be disseminated through student research projects and in action research, practitioner, and/or top-tiered journals.

\section{Caveats to this Article}

Before we conclude, there are some important caveats to mention. First, there are other important aspects of PBTE and HLPs that are beyond the scope of this article (e.g., creating and sustaining meaningful P-12 partnerships, revamping curricula, incentives, and staffing patterns in higher education and P-12 schools, and developing and refining HLPs for teachers of early childhood, sensory and physical impairments, and/or gifted and talented). These topics and others are discussed in more detail elsewhere for general (Ball \& Forzani, 2009; Grossman et al., 2009; Windschitl et al., 2012) and special educators (McLeskey et al., 2017; McLeskey \& Brownell, 2015). Second, HLPs are not being promoted as the only source of effective teaching practice. In fact, they are an initial skill set that must be broadened, refined, and supplemented with the conditional knowledge to know when and where to apply them. Similarly, there are other sources of "effective" instructional practices (e.g., Hattie, 2009, 2012; What Works Clearinghouse) that may be more appropriate for specific populations, subject matter, and/or instructional goals.

Third, while the article focuses on teaching practice, it does not diminish the important roles that cognitive, affective, and contextual factors play in teacher development. The intent here is to highlight practice-related issues that have received insufficient attention in previous teacher education research (Goe \& Cogshall, 2007; Lignugaris/Kraft et al., 2014; Wilson et al., 2002).

Lastly, this article was not intended to be a comprehensive guide for identifying, implementing, and evaluating all 22 HLPs. Specific HLPs were highlighted and used as examples to provide clarity for real-world application. Variability in the process of identifying, implementing, and evaluating HLPs for specific preparation programs cannot be understated. We believe, however, that the general concepts and processes discussed are salient to all 22 HLPs.

\section{Conclusion}

Learning to teach is not easy. Sitting in a classroom learning about content and pedagogy is no match for quality, practice-based opportunities for preservice teachers to integrate knowledge into instruction. CEC's 22 HLPs are a list of effective practices that SETs are expected to display with some degree of proficiency before exiting preparation programs. Special educators have begun to infuse HLPs into their preparation programs and clinical experiences, and the emergence of practice-based teacher education is likely to sustain this trend. As noted, more questions than answers exist regarding how to systematic identify, implement, and evaluate the use of HLPs in SET programs. Hopefully, this article will stimulate additional conversation around these important topics. 


\section{References}

Agran, M., Sinclair, T., Alper, S., Cavin, M., Wehmeyer, M., \& Hughes, C. (2005). Using self-monitoring to increase following-direction skills of students with moderate to severe disabilities in general education. Education and Training in Developmental Disabilities, 40(1), 3-13. https:// www.jstor.org/stable/23879767

Archer, A. L., \& Hughes, C. A. (2011). Explicit instruction: Effective and efficient teaching (what works for special-needs learners). Guilford Press.

Ball, D., \& Forzani, F. (2009). The work of teaching and the challenge of teacher education. Journal of Teacher Education, 60(5), 497-511. https://doi. org/10.1177\%2F0022487109348479

Barkham, M., \& Margison, F. (2007). Practice-based evidence as a complement to evidence-based practice: From dichotomy to chiasmus. In $\mathrm{C}$. Freeman \& M. Power (Eds.), Handbook of evidence-based psychotherapies: A guide for research and practice (pp. 443-476). Wiley \& Sons.

Belfiore, P. J. \& Lee, D. L. (2016). Shaping the field of general and special education: The role of evidence in practice, and practice in dissemination. Journal of Evidence-Based Practices for Schools, 15(2), 138-150.

Benedict, A., Foley, A., Holdheide, L., Brownell, M., \& Kamman, M. (2016). Learning to teach: A framework for crafting high-quality, practice-based opportunities. Collaboration for Effective Educator Development, Accountability, and Reform (CEEDAR) Center. http://cedar. education.ufl.edu/wp-content/uploads/2016/06/ Learning-to-Teach Rubric.pdf

Benedict, A., Holdheide, L., Brownell, M., \& Foley, A. (2016). Learning to teach practice-based preparation in teacher education. Collaboration for Effective Educator Development, Accountability, and Reform (CEEDAR) Center. http://cedar. education.uff.edu/wpcontent/uploads/2016/07/ Learning-to-Teach Rubric.pdf

Bryk, A. S. (2009). Support a science of performance improvement. (2009, April). Phi Delta Kappan, 90(8), 597-600. https://doi.org/10.1177\% $\underline{\text { 2F003172170909000815 }}$

Cook, B. G., \& Cook, L. (2016). Leveraging evidence-based practice through partnerships based on practice-based evidence. Learning Disabili- ties: A Contemporary Journal, 14, 143-157.

Cooper, J. O., Heron, T. E., \& Heward, W. L. (2020). Applied behavior analysis (3rd ed.). Pearson.

Cornelius, K. E., \& Nagro, S. A. (2014). Evaluating the evidence base of performance feedback in preservice special education teacher training. Teacher Education and Special Education, 37(2), 133-146. https://doi. org/10.1177\%2F0888406414521837

Council for Exceptional Children. (2015). What Every Special Educator Must Know: Professional Ethics and Standards. Author.

Council for Exceptional Children. (2017). High Leverage Practices for K-12 special education teachers. Arlington, VA: Author.

Council for Exceptional Children. (2020a). About the initial K-12 standards. Exceptionalchildren.org. https://exceptionalchildren.org/standards/initial-practice-based-professional-preparation-standards-special-educators

Council for Exceptional Children. (2020b). Cross walks: Alignment of the CEC high leverage practices with the CEC initial practice based professional preparation standards for special educators. Exceptionalchildren.org. https://highleveragepractices.org/standards/cross-walks

Dunst, C. J., Hamby, D. W., Howse, R. B., Wilkie, H., \& Annas, K. (2020). Research synthesis of meta-analyses of preservice teacher preparation practices in higher education. Higher Education Studies, 10(1), 29-47. https://doi.org/10.5539/hes. v10n1p29

Embry, D. D. (2004). Community-based prevention using low-cost, evidence-based kernals and behavior vaccines. Journal of Community Psychology, 32(5), 575-591. https://doi.org/10.1002/ jcop. 20020

Embry, D. D., \& Biglan, A. (2008). Evidence-based kernels: Fundamental units of behavioral influence. Clinical Child and Family Psychology Review, 11, 75-113. https://doi.org/10.1007/s10567008-0036-X

Ericsson, K. A. (2014). The road to excellence: The acquisition of expert performance in the arts and sciences, sports, and games. Psychology Press.

Fabiano, G. A., Pelham, W. E., Manos, M. J., Gnagy, E. M., Chronis, A. M., Onyango, A. N., et al. (2004). An evaluation of three time-out procedures for children with attention deficit/hyperac- 
tivity disorder. Behavior Therapy, 35(3), 449-469. https://doi.org/10.1016/S0005-7894(04)80027-3

Farkas, S., \& Duffett, A. (2010). Cracks in the ivory tower? The views of education professors circa 2010. FDR Group/Thomas B. Fordham Institute.

Forness, S. R. (2001). Special education and related services: What have we learned from meta-analysis? Exceptionality, 9(4),185-197. https://doi. org/10.1207/S15327035EX0904 3

Goe, L., \& Coggshall, J. (2007). The teacher preparation - teacher practices - student outcomes relationship in special education: Missing links and necessary connections. NCCTQ Research and Policy Brief. Washington, DC: National Comprehensive Center for Teacher Quality. Available from www.ncctq. org

Grossman, P., Hammerness, K., \& McDonald, M. (2009). Redefining teaching: Re-imagining teacher education. Teachers and teaching: Theory and Practice. 15(2), 273-290. https://doi. org/10.1080/13540600902875340

Hauser, M., \& Kavanagh, S. S. (2019). Practice-based teacher education. Oxford Research

Encyclopedia of Education. https://doi. org/10.1093/acrefore/9780190264093.013.419

Hattie, J. (2009). Visible learning: A synthesis of over 800 meta-analyses relating to achievement. Taylor \& Francis.

Hattie, J. (2012). Visible learning for teachers: Maximizing impact on learning. Routledge.

Hughes, C., Copeland, S. R., Agran, M., Wehmeyer, M. L., Rodi, M. S., \& Presley, J. A. (2002). Using self-monitoring to improve performance in general education high school classes. Education and Training in Mental Retardation and Developmental Disabilities, 37, 262-272. https://www.jstor. org/stable/23880004

Kazdin, A. E. (1980). Acceptability of alternative treatments for deviant child behavior. Journal of Applied Behavior Analysis, 13(2), 259-273. https://doi.org/10.1901/jaba.1980.13-259

Kretlow, A. G., \& Bartholomew, C.C. (2010). Using coaching to improve the fidelity of evidence-based practices: A review of studies. Teacher Education and Special Education, 33(4), 279-299. https://doi. org/10.1177\%2F0888406410371643

Ledford, J. R., Barton, E. E., Severini, K. E., \& Zim- merman, K. N. (2019). A primer on single-case research designs: Contemporary use and analysis. American journal on intellectual and developmental disabilities, 124(1), 35-56. https://doi. org/10.1352/1944-7558-124.1.35

Leko, M. M., Brownell, M. T., Sindelar, P. T., \& Kiely, M. T. (2015). Envisioning the future of special education personnel preparation in a standards-based era. Exceptional Children, 82(1), 25-43. https://doi. org/10.1177\%2F0014402915598782

Lignugaris/Kraft, B., Sindelar, P. T., McCray, E. dD., \& Kimerling, J. (2014). The "wicked question" of teacher education effects and what to do about it. In P. T. Sindelar, E. D. McCray, M. T. Brownell, \& B. Lignugaris/Kraft (Eds.). Handbook of research on special education teacher preparation (pp. 461-471). Routledge.

Maag, J. W., Rutherford, R. B., Wolchik, S. A., \& Parks, B. T. (1986). Comparison of two short overcorrection procedures on the stereotypic behavior of autistic children. Journal of Autism and Developmental Disorders, 16(1), 83-87. https:// doi.org/10.1007/BF01531581

Maheady, L., Jabot, M., Rey, J., \& Michielli-Pendl, J. (2007). An early field based experience and its effects on pre-service teachers' practice and student learning. Teacher Education and Special Education 30, 24-33. https://doi.org/10.1177\% 2F088840640703000103

Maheady, L., Patti, A., Rafferty, L., \& del Prado Hill, P. (2019). School-university partnerships: One institution's efforts to integrate and support teacher use of high-leverage practices. Remedial and Special Education, 40(6), 346-354. https://doi. org/10.1177\%2F0741932518812689

Maheady, L. J., \& Patti, A. L. (2020). High Leverage Practices in Elementary Inclusive Education. In Oxford Research Encyclopedia of Education. https://doi.org/10.1093/acrefore/9780190264093.013.1180

Maheady, L., Sacca, M. K., \& Harper, G. F. (1988). Classwide peer tutoring with mildly handicapped high school students. Exceptional Children, 55(1), 52-59. https://doi.org/10.1177\% 2F001440298805500106

Maheady, L., Smith, C. \& Jabot, M. (2013). Utilizing evidence-based practice in teacher preparation. Cook, B.G., Tankersley, M. \& Landrum, T.J. 
(Eds.) Evidence-based practices (advances in learning and behavioral disabilities, Vol. 26), Emerald Group Publishing Limited, Bingley, pp. 121-147. https://doi.org/10.1108/S0735004X(2013)0000026008

McDonald, M., Kazemi, E., \& Kavanaugh, S. (2013). Core practices of teacher education: A call for a common language and collective activity. Journal of Teacher Education, 64(5), 378-386. https://doi. org/10.1177\%2F0022487113493807

McLeskey, J., Barringer, M., Billingsley, B., Brownell, M., Jackson, D., Kennedy, M., Lewis, T.,

Maheady, L., Rodriguez, J., Scheeler, M., Winn, J., \& Ziegler, D. (2017). High leverage practices in special education: The final report of the HLP Writing Team. Arlington, VA: CEC \& CEEDAR Center.

McLeskey, J., \& Billingsley, B. (2008). How does the stability of the teaching force influence the research-to-practice gap? A perspective on the teacher shortage in special education. Remedial and Special Education, 29(5), 293-305. https:// doi.org/10.1177\%2F0741932507312010

McLeskey, J., \& Brownell, M. (2015). High-leverage practices and teacher preparation in special education (Document No. PR-1). Retrieved from University of Florida, Collaboration for Effective Educator, Development, Accountability, and Reform Center website: http://ceedar.education.ufl. edu/tools/best-practice-review/National Council for Accreditation of Teacher Education (2010, November). Transforming teacher education through clinical practice: A national strategy to prepare effective teachers. Washington, DC: NCATE. Retrieved from www.ncate.org/publications.

Nye, N., Konstantopoulos, S., \& Hedges, L. (2004). How large are teacher effects? Educational Evaluation and Policy Analysis, 26(3), 237-257. https://doi.org/10.3102\%2F01623737026003237

Patti, A., Budin, S., Rafferty, L., \& Maheady, L., (2021). The role of high leverage practices in effective inclusive elementary classrooms. In J. McLeskey, F. Spooner, B. Algozzine, \& N. L. Waldron (Eds.), Handbook of Effective Inclusive Elementary Schools: Research and Practice (2nd Edition).

Pugach, M. C., Blanton, L. P., \& Boveda, M. (2014). Working together research on the preparation of general education and special education teachers for inclusion and collaboration. In P. T. Sindelar, E. D. McCray, M. T. Brownell, \& B. Lignugaris-Kraft (Eds.), Handbook of research on special education teacher preparation (pp. 143-160). Routledge.

Riden, B. S., Markelz, A. M., Ruiz, S., Kent, S., Pavelka, S. K., \& Chitiyo, A. (2020). The nature and extent of component analyses for improving or mitigating behavior a systematic review. Behavior Modification. https://doi. org/10.1177\%2F0145445520971256

Riley-Tillman, T. C., \& Chafouleas, S. M. (2003). Using interventions that exist in the natural environment to increase treatment integrity and social influence in consultation. Journal of Educational and Psychological Consultation, 14(2), 139-156. https://doi.org/10.1207/s1532768xjepc1402 3

Rowan, B. (2004). Teachers matter: Evidence from value-added assessments. AERA Research Points 2(2). http://www.aera.net/Portals/38/docs/Publications/Teachers\%20Matter.pdf

Sindelar, P. T., Washburn-Moses, L., Thomas, R. A., \& Leko, C. D. (2014). The policy and economic contexts of teacher education. In P. T. Sindelar, E. D. McCray, M. T. Brownell, \& B. Lignugaris/ Kraft (Eds.). Handbook of research on special education teacher preparation (pp. 3-16.). Routledge.

States, J., Detrich, R., \& Keyworth, R. (2012). Effective teachers make a difference. In R. Detrich, R. Keyworth, \& J. States (Eds.), Advances in evidence-based education (Vol. 2): Education at the crossroads: The state of teacher preparation (pp. 1-45). Oakland, CA: The Wing Institute.

Ward-Horner, J., \& Sturmey, P. (2010). Component analyses using single-subject experimental designs: A review. Journal of Applied Behavior Analysis, 43(4), 685-704. https://doi.org/10.1901/ jaba.2010.43-685

Wilson, S., Floden, R., \& Ferrini-Mundy, J. (2002). Teacher preparation research: An insider's view from the outside. Journal of Teacher Education, 53, 190-204. https://doi.org/10.1177\% 2F0022487102053003002

Windschitl, M., Thompson, J., Braaten, M., \& Stroupe, D. (2012). Proposing a core set of instructional practices and tools for teachers of science. Science Education, 96(5), 878-903. https://doi. 
org/10.1002/sce.21027

Vogl, K., \& Preckel, F. (2014). Full-time ability grouping of gifted students: Impacts on social self-concept and school-related attitudes. Gifted Child Quarterly, 58(1), 51-68. https://doi. org/10.1177\%2F0016986213513795

Zeichner, K. (2012). The turn once again toward practice-based teacher education. Journal of Teacher Education, 63(5), 376-382. https://doi. org/10.1177\%2F0022487112445789

\section{About the Authors}

\section{Andrew M. Markelz}

Andrew M. Markelz is an assistant professor and coordinator of the special education director license program at Ball State University. Dr. Markelz is editor of the Journal of Special Education Preparation and co-author of The Essentials of Special Education Law. The focus of his research is on expediting the novice-to-expert teaching curve in proactive classroom management strategies and issues related to special education law.

\section{Benjamin S. Riden}

Benjamin S. Riden, PhD, BCBA-D is an assistant professor at James Madison University. His research interests include using the principles of applied behavior analysis to support students with challenging behavior in schools, preparing teachers to effectively manage their classrooms, and single-case research design.

\section{Lawrence Maheady}

Dr. Lawrence Maheady is Professor and Horace Mann Endowed Chair in the Exceptional Education Department at SUNY Buffalo State. He prepares pre-service and in-service teachers, conducts classroom-based research, and collaborates with school districts locally and nationally. Dr. Maheady has authored or co-authored over 90 articles in peer-reviewed journals, 12 book chapters, and two books; presented his work at over 200 international, national, and state-level conferences; and conducted more than 300 staff development sessions in 29 different states. 